\title{
Salivary microflora and mode of delivery: a prospective case control study
}

\author{
Katarina Boustedt ${ }^{1,2^{*}}$, Josefine Roswall ${ }^{2,3}$, Gunnar Dahlén ${ }^{4}$, Jovanna Dahlgren ${ }^{2}$ and Svante Twetman ${ }^{1,5}$
}

\begin{abstract}
Background: Previous cross-sectional studies have suggested that the mode of delivery can influence the composition of oral microflora. The aim of this prospective study was to compare the salivary colonization in vaginally delivered children with children delivered by Caesarian section (C-section) during their first 6 months of life.

Methods: The study group consisted of 149 consecutively enrolled infants, delivered either vaginally $(n=96)$ or by Csection $(n=53)$ that volunteered after consent of their parents. Saliva samples were collected within 2 days after birth and then after 1, 3, and 6 months. A saliva sample from the mothers was obtained 6 months after delivery. The parents were asked to complete a questionnaire on socioeconomic factors, lifestyle, and hygiene at baseline and throughout the study period. All samples were analyzed with 13 pre-determined bacterial probes using checkerboard DNA-DNA hybridization.
\end{abstract}

Results: The groups were balanced at baseline concerning all relevant background factors. Gram-positive streptococci (S. mitis, S. salivarius) displayed the highest counts in both groups but a greater diversity was observed in the vaginally delivered group. A. naeslundi, A. odontolytics, F. nucleatum and L. salivarius were only detected among the vaginally delivered infants. The prevalence of S. sanguinis, S. gordoni, R. denticariosa, and B. dentinum increased by age in both groups but the prevalence was significantly lower in the $C$-section group $(p<0.05)$. There was a link between the mothers and their offspring's concerning the salivary microbial profile.

Conclusion: The microbial composition in saliva differs by the mode of delivery during the first six months of life.

Keywords: C-section, Infants, Oral bacteria, Oral colonization, Saliva

\section{Background}

The oral biofilm plays a significant role in health and disease [1]. The composition is highly individual and affected by factors such as genetics, diet, age and level of hygiene [2]. According to the hygiene hypothesis, the sequence and timing of exposure to a variety of bacterial strains early in life seem to be of importance for the gut colonization [3]. The mode of delivery and cessation of breastfeeding have been identified as major factors in gut microbiota maturation [4], and this seems applicable also to the oral cavity. Previous research has indicated that children delivered by caesarian section (C-section) exhibit a reduced microbial diversity in saliva in

\footnotetext{
* Correspondence: katarina.boustedt@regionhalland.se

'Maxillofacial Unit, Halland Hospital, SE-30185 Halmstad, Sweden

${ }^{2}$ Department of Pediatrics, The Sahlgrenska Academy, University of

Gothenburg, Box 400 SE-40530 Gothenburg, Sweden

Full list of author information is available at the end of the article
}

comparison with vaginally delivered children $[5,6]$. Moreover, the oral microbial profile can discriminate breast-fed from formula-fed infants [7]. The long-term clinical importance of these findings is not fully clear but a reduced diversity in the guts correlates to increased risk of developing chronic disease such as asthma and allergy [8]. The information of lower diversity in C-sectioned infants is however mainly derived from cross-sectional studies and few longitudinal data are available. The aim of the present study was to analyze saliva samples from infants delivered with Csection through their first six months of life with respect to selected key bacteria. The results were compared with a group of vaginally delivered children and the null hypothesis was that no differences would be displayed between the groups.

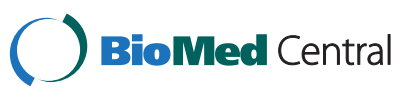

(c) 2015 Boustedt et al. Open Access This article is distributed under the terms of the Creative Commons Attribution 4.0 International License (http://creativecommons.org/licenses/by/4.0/), which permits unrestricted use, distribution, and reproduction in any medium, provided you give appropriate credit to the original author(s) and the source, provide a link to the Creative Commons license, and indicate if changes were made. The Creative Commons Public Domain Dedication waiver (http://creativecommons.org/publicdomain/zero/1.0/) applies to the data made available in this article, unless otherwise stated. 


\section{Methods}

\section{Study design}

The investigation employed a prospective case-control design and was ethically approved by the Regional Ethics Committee in Lund, Sweden (Dnr 2012/483) who has the authority to approve studies at Halland Hospital.

\section{Study group}

The material consisted of 149 newborn infants delivered either vaginally (V; $n=96$ ) or by C-section (CS; $n=53$ ). The participants were consecutively enrolled among healthy volunteers that were born at Halland Hospital, Halmstad, Sweden, between April and December 2013. Both parents signed a consent form after thorough verbal and written information. Exclusion criteria were i) preterm children, ii) neonates in need of neonatal care, iii) infants with an unclear medical condition, and iv) families that planned relocation abroad after birth. The 6-month attrition rate was $20 \%$ and the drop-outs with respect to the designated follow-ups are shown in Table 1.

\section{Saliva sampling}

Samples of saliva were collected within 2 days after birth and then after 1, 3 and 6 months with aid of sterile cotton buds. At the first occasion, the parents were carefully instructed and shown how to collect the sample and transfer the top to a marked plastic tube. At the designated follow-ups, the parents received the test kit with a sterile containing a cotton bud and a plastic tube with an illustrated information sheet via surface mail. The parents were requested to collect the sample in the morning by soaking the cotton bud in saliva and immediately return it to the laboratory. When a sample was missing, the parents were reminded through a telephone call within 5 days. In a similar way, a saliva sample from the mothers was obtained 6 months after delivery. All samples were stored frozen until further analyses.

\section{Microbial method}

The samples were processed with the checkerboard DNA-DNA hybridization technology according to WallManning et al. [9]. DNA was extracted with mutanolysin and lysozyme as previously described [10] and the DNA

Table 1 Participants and drop-out frequency in the two groups (CS = C-section; $V=$ vaginal delivery)

\begin{tabular}{lllll}
\hline Age & CS & $V$ & Total & dropout rate \\
\hline Newborn (1-2 days) & 53 & 95 & 148 & - \\
1 month & 45 & 79 & 124 & $16 \%$ \\
3 months & 44 & 74 & 118 & $20 \%$ \\
6 months & 44 & 73 & 117 & $20 \%$ \\
\hline
\end{tabular}

Values in the table denote number of children quality was evaluated from the UV spectrum between 200 and $300 \mathrm{~nm}$ using a Gene Quant spectrophotometer (Pharmacia Biotech, Uppsala, Sweden). Whole genomic DNA probes of potential interest for oral health and disease were prepared from a panel of 13 bacterial species with strain designation according to the culture collection Oral Microbiology, Gothenburg, Sweden: Actinomyces odontolyticus G67; Actinomyces naeslundii 2466 (A. oris); Bifidobacterium dentium G174; Fusobacterium nucleatum 2865; Lactobacillus casei 3184; Lactobacillus salivarius 3830; Rothia denticariosa 1956; Streptococcus gordonii 2471; Streptococcus mitis 1770; Streptococcus mutans 2482; Streptococcus salivarius 2473; Streptococcus sanguinis 2478; Veillonella parvula G186. The bacterial counts were obtained by the percent-method in which the intensity of the signal (biomedical light units) was expressed as a fraction of a high standard sample $\left(10^{6}\right.$ cells) with aid of Lumilmager Workstation (Boehringer Mannheim, Mannheim, Germany). The detection level was $>10^{4}$ cells per $\mathrm{mL}$ sample.

\section{Questionnaire}

At the inclusion, the parents were asked to complete a 20-item questionnaire on the family characteristics, socio-economy, lifestyle factors and hygiene habits. A further questionnaire on breeding, feeding, tooth brushing habits and prescribed antibiotics was attached to the follow-up mailings and returned together with the samples.

\section{Statistical methods}

All data were processed with the IBM-SPSS software (version 22.0; Chicago IL, USA). Differences in percentage distributions between the groups were calculated with chi-square tests and correlations between the bacterial counts in mothers and their offspring's were expressed as Spearman correlation coefficient. We considered $p$-values less than 0.05 as statistically significant.

\section{Results}

The groups were balanced at baseline concerning all relevant background factors, except for the water break (for exact details, see Table 2). The proportion of girls was somewhat higher in the CS group but the difference was not statistically significant. The self-reported feeding routines and the use of pacifiers are shown in Table 3. Infant formulas were more common in CS group compared with the $\mathrm{V}$ group during the first 6 months but the difference did not reach statistical significance. The frequency of prescribed antibiotics to the mothers during the first six months after delivery was similar $(<15 \%)$ in both groups. The total number of cells detected from the $\mathrm{V}$ samples was on average higher than the CS samples at all sampling occasions: birth: 0.7 vs. 
Table 2 Baseline family characteristics in the two groups (CS = C-section; $V=$ vaginal delivery)

\begin{tabular}{lll}
\hline Variable & CS & V \\
\hline Sex (girls/boys) & $57 / 43$ & $44 / 56$ \\
Water break (yes) & 29 & $100^{\mathrm{a}}$ \\
Mother born in Sweden (yes) & 91 & 91 \\
Mother's education, university (yes) & 64 & 60 \\
Mother smoking (yes) & 0 & 4 \\
Prescribed antibiotics (mother) & 4 & 4 \\
Siblings (>2) & 6 & 6 \\
\hline
\end{tabular}

Values in the table denote percent.

${ }^{\mathrm{a}}$ statistically significant difference between the groups $(p<0.05$,

chi-square test)

$0.5 \times 10^{6} ; 1$ month: 1.3 vs. $0.9 \times 10^{6} ; 3$ months: 1.6 vs $0.9 \times 10^{6} ; 6$ months: 1.5 vs $0.9 \times 10^{6}$ cells. The prevalence of the selected bacteria is summarized in Table 4. A greater diversity was observed in the $\mathrm{V}$ group. For example, A. naeslundi, A. odontolytics, $F$. nucleatum and $L$. salivarius were only detected among the vaginally delivered infants. The prevalence of $S$. sanguinis, S. gordoni, $R$. denticariosa and $B$. dentinum increased with age in both groups but the prevalence was significantly lower in the CS group $(p<0.05)$. S. mitis and S. salivarius displayed the highest counts in both groups at all samplings but the counts were not associated with the mode of delivery. There was a statistically significant correlation between the mothers and their offspring's concerning the salivary profile six months after the delivery with respect to five strains in the CS group and eight strains in the V group (Table 5).

\section{Discussion}

The results of this relatively large study lend further support to previous findings that the composition of the oral biofilm is affected by the mode of delivery $[5,6,11]$ with a lower diversity among infants delivered with C-

Table 3 Self-reported data from the questionnaires distributed 1,3 and 6 months after vaginal delivery $(V)$ or C-section (CS)

\begin{tabular}{llll}
\hline Variable & 1 month & 3 months & 6 months \\
& CSN & CSN & CSN \\
\hline Breast feeding (yes) & $89 / 95$ & $71 / 84$ & $55 / 69$ \\
Infant formula (yes) & $47 / 32$ & $51 / 35$ & $50 / 44$ \\
Introduced food-tasting (yes) & $0 / 0$ & $0 / 4$ & $72 / 83$ \\
Pacifier (yes) & $80 / 83$ & $82 / 77$ & $85 / 71$ \\
Teeth present (yes) & $0 / 0$ & $2 / 0$ & $30 / 32$ \\
Oral cleaning (yes) & $0 / 0$ & $9 / 3$ & $30 / 26$ \\
Antibiotics (yes, infant) & $0 / 3$ & $0 / 1$ & $0 / 1$ \\
Antibiotics (yes, mothers) & $9 / 5$ & $5 / 4$ & $0 / 3$ \\
\hline
\end{tabular}

Values in the table denote percent
Table 4 Prevalence ( $\geq 10^{4}$ cells) of the selected strains at birth and designated time intervals in children delivered vaginally $(V)$ or with C-section (CS)

\begin{tabular}{lllll}
\hline Strain & birth & 1 month & 3 months & 6 months \\
& CSN & CSN & CSN & CSN \\
\hline A. naeslundi & $0 / 5$ & $0 / 0$ & $0 / 2$ & $0 / 2$ \\
A. odontolyticus & $0 / 12^{\mathrm{a}}$ & $0 / 32^{\mathrm{a}}$ & $0 / 30^{\mathrm{a}}$ & $0 / 32^{\mathrm{a}}$ \\
B. dentinum & $5 / 32^{\mathrm{a}}$ & $13 / 61^{\mathrm{a}}$ & $8 / 49^{\mathrm{a}}$ & $16 / 63^{\mathrm{a}}$ \\
F. nucleatum & $0 / 2$ & $0 / 11$ & $0 / 10$ & $0 / 14^{\mathrm{a}}$ \\
L. casei & $0 / 2$ & $0 / 0$ & $0 / 0$ & $0 / 0$ \\
L. salivarius & $0 / 0$ & $0 / 0$ & $0 / 0$ & $0 / 3$ \\
R. denticariosa & $0 / 12^{\mathrm{a}}$ & $3 / 22^{\mathrm{a}}$ & $10 / 21$ & $8 / 39^{\mathrm{a}}$ \\
S. gordoni & $3 / 15^{\mathrm{a}}$ & $10 / 19$ & $13 / 32^{\mathrm{a}}$ & $13 / 38^{\mathrm{a}}$ \\
S. mitis & $73 / 84$ & $85 / 94$ & $90 / 94$ & $93 / 96$ \\
S. mutans & $53 / 76^{\mathrm{a}}$ & $65 / 88^{\mathrm{a}}$ & $58 / 88^{\mathrm{a}}$ & $68 / 92^{\mathrm{a}}$ \\
S. salivarius & $28 / 36$ & $45 / 67^{\mathrm{a}}$ & $53 / 71$ & $48 / 70$ \\
S. sanguinis & $0 / 35^{\mathrm{a}}$ & $5 / 44^{\mathrm{a}}$ & $10 / 47^{\mathrm{a}}$ & $13 / 53^{\mathrm{a}}$ \\
V. parvula & $0 / 0$ & $3 / 6$ & $5 / 6$ & $8 / 24$ \\
\hline
\end{tabular}

Values in the table denote percent

${ }^{\mathrm{a}}$ statistically significant difference between the groups $(p<0.05$, chi-square test)

section. Hence, the null hypothesis could be rejected. Our results must however be considered with some caution for a number of reasons. First of all, the composition of the early salivary microbiota may be influenced by a number of factors other than the mode of delivery, such as peri-delivery treatment with antibiotics, diet [12], feeding practices [7, 13], use of pacifiers [14], family income [11, 13], and tooth brushing habits [15]. In our study, the CS and the vaginally delivered groups were

Table 5 Oral colonization of selected bacteria in mothers and their infants, 6 months after vaginal delivery ( $V$ ) or C-section (CS)

\begin{tabular}{lll}
\hline Strain & CS & V \\
\hline A. naeslundi & NS & NS \\
A. odontolyticus & NS & 0.43 \\
B. dentinum & 0.54 & 0.28 \\
F. nucleatum & NS & NS \\
L. casei & NS & NS \\
L. denticariosa & NS & 0.45 \\
L. salivarius & NS & NS \\
S. gordonii & 0.48 & 0.36 \\
S. mitis & 0.59 & 0.32 \\
S. mutans & 0.85 & 0.36 \\
S. salivarius & 0.71 & 0.48 \\
S. sanguinis & NS & 0.56 \\
V. parvula & NS & NS \\
\hline
\end{tabular}

The values in table denote Spearman two-tailed correlation coefficient. NS Not statistically significant 
similar with respect to socio-economy, family size, maternal education level, and feeding behavior so we consider the risk for confounders as small. Even the prescription of antibiotics to the mothers and their offsprings was equal according to the questionnaires, albeit a certain underreporting may be suspected. Secondly, the checkerboard DNA-DNA hybridization technique has its strengths and limitations; the main advantage is that the method permits enumeration of large numbers of species in large numbers of samples and hence, considered as a useful tool for the enumeration of bacterial species in complex microbial systems [16]. Among the limitations, possible cross-reactions and varying reproducibility for different strains has been discussed [17]. Thirdly, it is possible that the sampling procedure may have caused a greater variability in results than the laboratory procedure as such. These shortcomings, together with the relatively high detection level made us to quantify the bacterial data according to the percent method as being the most reliable alternative [17]. It is however important to underline that the prevalence values reported here was based on a threshold level of approximately $10^{4}$ cells; the selected strains could very well be present in the samples but not in enough amounts to be detected. Thus, the next natural step would therefore be to extend the mapping to include the entire oral microbiome. A fourth possible bias was the relatively high dropout rate during the course of the study, and we can only speculate on its possible influence on the results.

The intra-family correlation of the oral microflora with special reference to mother-child and mutans streptococci acquisition has been described several times before [18-21]. Interestingly, Ruiz-Rodriguez and co-workers [22] failed to demonstrate a mother-child relationship for $S$. mutans with conventional culturing but their sample was small and $S$. mutans was very rarely detected (2\%) among the infants at the age of 150 days. In the present study, the majority of all children in the CS group and almost all in the $\mathrm{V}$ group harbored $S$. mutans at 6 months of age and apart from the different sampling and analytical techniques, we have no explanation to these contrasting findings. Nevertheless, the clear mother-child correlation for 8 of the 13 stains in the $\mathrm{V}$ group was interesting but needs to be further investigated with for example $16 \mathrm{~s}$ rDNA amplification and sequencing.

The question for how long a delivery-dependent difference in oral colonization prevails, and whether this may affect dental health later in life, remains open. There is however fair evidence that an early acquisition of oral mutans streptococci in general is associated with an increased risk for caries development [23, 24]. Furthermore, there are reports suggesting that children delivered with
C-section have an elevated risk for childhood asthma [25] and more dental caries at the age of $3-5$ years [26, 27]. This possible relationship needs however to be verified in larger settings and in prospective studies covering the young permanent dentition.

\section{Conclusions}

Within the limitations of the present study, it was concluded that mode of delivery plays a role in the composition of the oral biofilm during the first 6 months of life. Vaginally delivered children appear to have a greater diversity than $\mathrm{C}$-section children and a closer similarity with their mothers. Further studies to investigate a possible long-term influence on oral health seem warranted.

\section{Abbreviation}

CS: Caesarian section.

\section{Competing interests}

The authors have no conflict of interest to declare.

\section{Authors' contributions}

KB: collected all data, performed statistical analyses and wrote the first draft. JR: designed the study, and finalized the manuscript. GD: performed the microbial analyses and wrote the manuscript. JD: designed and supervised the study and finalized the manuscript. ST: designed the study, performed statistical analyses and wrote the first draft. All authors have read and approved the final manuscript.

\section{Acknowledgments}

The project was supported by a grant from Region Halland, Sweden. The authors would like to thank the staff at the maternal clinic at the Halland Hospital and all parents for their trust and patience. The late Mrs. Kerstin Magnusson $(\mathrm{RDH})$ is acknowledged for her skilled technical assistance.

\section{Author details}

${ }^{1}$ Maxillofacial Unit, Halland Hospital, SE-30185 Halmstad, Sweden. ${ }^{2}$ Department of Pediatrics, The Sahlgrenska Academy, University of Gothenburg, Box 400SE-40530 Gothenburg, Sweden. ${ }^{3}$ Department of Pediatrics, Halland Hospital, SE-30185 Halmstad, Sweden. ${ }^{4}$ Department of Odontology, The Sahlgrenska Academy, University of Gothenburg, Box 400SE-40530 Gothenburg, Sweden. ${ }^{5}$ Department of Odontology, Faculty of Health and Medical Sciences, University of Copenhagen, Nörre Allé 20, Copenhagen N, Denmark.

Received: 16 July 2015 Accepted: 27 November 2015

Published online: 03 December 2015

\section{References}

1. Zarco MF, Vess TJ, Ginsburg GS. The oral microbiome in health and disease and the potential impact on personalized dental medicine. Oral Dis. 2012; 18:109-20.

2. Marsh PD, Devine DA. How is the development of dental biofilms influenced by the host? J Clin Periodontol. 2011;38 Suppl 11:28-35.

3. Adlerberth I, Wold AE. Establishment of the gut microbiota in Western infants. Acta Paediatr. 2009;98:229-38.

4. Bäckhed F, Roswall J, Peng Y, Feng Q, Jia H, Kovatcheva-Datchary P, et al. Dynamics and stabilization of the human gut microbiome during the first year of life. Cell Host Microbe. 2015;17:690-703.

5. Nelun Barfod M, Magnusson K, Lexner MO, Blomqvist S, Dahlén G, Twetman S. Oral microflora in infants delivered vaginally and by caesarean section. Int J Paediatr Dent. 2011;21:401-6.

6. Lif Holgerson P, Harnevik L, Hernell O, Tanner AC, Johansson I. Mode of birth delivery affects oral microbiota in infants. J Dent Res. 2011;90:1183-8.

7. Holgerson PL, Vestman NR, Claesson R, Ohman C, Domellöf M, Tanner AC, et al. Oral microbial profile discriminates breast-fed from formula-fed infants. J Pediatr Gastroenterol Nutr. 2013;56:127-36 
8. Ege MJ, Mayer M, Normand AC, Genuneit J, Cookson WO, Braun-Fahrländer C, et al. Exposure to environmental microorganisms and childhood asthma. N Engl J Med. 2011;24(364):701-9.

9. Wall-Manning GM, Sissons CH, Anderson SA, Lee M. Checkerboard DNADNA hybridisation technology focused on the analysis of Gram-positive cariogenic bacteria. J Microbiol Methods. 2002;51:301-11.

10. Teanpaisan R, Dahlen G. Use of polymerase chain reaction techniques and sodium dodecyl sulfatepolyacrylamide gel electrophoresis for differentiation of oral Lactobacillus species. Oral Microbiol Immunol. 2006;21:79-83.

11. Li Y, Caufield PW, Dasanayake AP, Wiener HW, Vermund SH. Mode of delivery and other maternal factors influence the acquisition of Streptococcus mutans in infants. J Dent Res. 2005;84:806-11.

12. Habibian M, Beighton D, Stevenson R, Lawson M, Roberts G. Relationships between dietary behaviours, oral hygiene and mutans streptococci in dental plaque of a group of infants in southern England. Arch Oral Biol. 2002:47:491-8.

13. Thakur R, Singh MG, Chaudhary S, Manuja N. Effect of mode of delivery and feeding practices on acquisition of oral Streptococcus mutans in infants. Int J Paediatr Dent. 2012;22:197-202.

14. Hesselmar B, Sjöberg F, Saalman R, Aberg N, Adlerberth I, Wold AE. Pacifier cleaning practices and risk of allergy development. Pediatrics. 2013;131: e1829-37.

15. Plonka KA, Pukallus ML, Barnett AG, Walsh LJ, Holcombe TF, Seow WK. A longitudinal study comparing mutans streptococci and lactobacilli colonisation in dentate children aged 6 to 24 months. Caries Res. 2012;46: 385-93.

16. Socransky SS, Haffajee AD, Smith C, Martin L, Haffajee JA, Uzel NG, et al. Use of checkerboard DNA-DNA hybridization to study complex microbial ecosystems. Oral Microbiol Immunol. 2004;19:352-62.

17. Dahlén G, Preus HR, Baelum V. Methodological issues in the quantification of subgingival microorganisms using the checkerboard technique. J Microbiol Methods. 2015;110:68-77.

18. Thorild I, Lindau-Jonson B, Twetman S. Prevalence of salivary Streptococcus mutans in mothers and in their preschool children. Int J Paediatr Dent. 2002;12:2-7.

19. Kishi M, Abe A, Kishi K, Ohara-Nemoto Y, Kimura S, Yonemitsu M. Relationship of quantitative salivary levels of Streptococcus mutans and S. sobrinus in mothers to caries status and colonization of mutans streptococci in plaque in their 2.5-year-old children. Community Dent Oral Epidemiol. 2009;37:241-9.

20. Mannaa A, Carlén A, Dahlén $G$, Lingström P. Intra-familial comparison of supragingival dental plaque microflora using the checkerboard DNA-DNA hybridisation technique. Arch Oral Biol. 2012;57:1644-50.

21. Virtanen JI, Vehkalahti KI, Vehkalahti MM. Oral health behaviors and bacterial transmission from mother to child: an explorative study. BMC Oral Health. 2015;15:75.

22. Ruiz-Rodriguez $S$, Lacavex-Aguilar $V$, Pierdant-Perez M, Mandeville $P$, Santos-Diaz M, Garrocho-Rangel A, et al. Colonization levels of Streptococcus mutans between mother and infant: a postnatal prospective cohort study. J Clin Pediatr Dent. 2014;38:197-200.

23. Thenisch NL, Bachmann LM, Imfeld T, Leisebach Minder T, Steurer J. Are mutans streptococci detected in preschool children a reliable predictive factor for dental caries risk? A systematic review. Caries Res. 2006;40:366-74.

24. Parisotto TM, Steiner-Oliveira C, Silva CM, Rodrigues LK, Nobre-dos-Santos M. Early childhood caries and mutans streptococci: a systematic review. Oral Health Prev Dent. 2010;8:59-70.

25. Thavagnanam S, Fleming J, Bromley A, Shields MD, Cardwell CR. A metaanalysis of the association between Caesarean section and childhood asthma. Clin Exp Allergy. 2008;38:629-33.

26. Barfod MN, Christensen LB, Twetman S, Lexner MO. Caries prevalence in Danish pre-school children delivered vaginally and by caesarean section. Acta Odontol Scand. 2012;70:190-3.

27. Pattanaporn K, Saraithong $P$, Khongkhunthian $\mathrm{S}$, Aleksejuniene J, Laohapensang P, Chhun N, et al. Mode of delivery, mutans streptococci colonization, and early childhood caries in three- to five-year-old Thai children. Community Dent Oral Epidemiol. 2013;41:212-23.

\section{Submit your next manuscript to BioMed Central and we will help you at every step:}

- We accept pre-submission inquiries

- Our selector tool helps you to find the most relevant journal

- We provide round the clock customer support

- Convenient online submission

- Thorough peer review

- Inclusion in PubMed and all major indexing services

- Maximum visibility for your research

Submit your manuscript at www.biomedcentral.com/submit 